\title{
Spatiotemporal Trends in Episodic Ozone Pollution in the Lower Fraser Valley, British Columbia, in Relation to Mesoscale Atmospheric Circulation Patterns and Emissions
}

\author{
B. Ainslie And D. G. Steyn \\ Atmospheric Science Programme, The University of British Columbia, Vancouver, British Columbia, Canada
}

(Manuscript received 7 October 2005, in final form 8 January 2007)

\begin{abstract}
A cluster analysis of wind measurements from two meteorological stations in the Lower Fraser Valley, British Columbia, Canada, has been performed to identify mesoscale circulation regimes that are common to days on which ozone mixing ratios at one or more measuring stations in the region's fixed monitoring network exceed the National Ambient Air Quality Objective of $82 \mathrm{ppb}$. The analysis, using $20 \mathrm{yr}$ of data (1984-2003), identifies the following four regimes: two with morning winds at the coastal Vancouver International Airport (YVR) meteorological station from the northwest direction and two with southerly YVR morning winds. Not all exceedance days are associated with sea-breeze circulations, but days with southerly morning winds have a higher proportion of well-developed sea-breeze circulations. Composite synoptic patterns associated with each regime all show high pressure over the eastern Pacific Ocean with a thermal trough over Washington State and southwestern British Columbia. Composite ozone patterns, corresponding to each mesoscale circulation regime and taken at the hour of maximum ozone concentration, show similar general features, including strong ozone titration in and around the urban source regions and higher values downwind. This suggests that precursor buildup, prior to the exceedance day, plays an important role in the spatial ozone pattern on exceedance days. A simple multiple linear regression of the plume centroid with the number of days elapsed from the start of the analysis period suggests the centroid of the ozone plume has shifted eastward since 1990. There also appears to be a north-south shift in the ozone plume. It is impossible to tell if these shifts are due to changes in emission levels or to changes in spatial emission patterns, because both changes have occurred over the study period.
\end{abstract}

\section{Introduction}

Ground level ozone is a harmful pollutant pervasive in and around many urbanized areas (United Nations Environmental Programme 1992). Knowledge of its spatial extent and diurnal temporal behavior is important for assessing health (Mulholland et al. 1998) and vegetation (Van Ooy and Carroll 1995) impacts, communicating air-quality advisories to the public (Abraham and Comrie 2004), and designing fixed monitoring networks (Peterson 2000). Complicating any spatiotemporal analysis of ozone is the fact that it is not directly emitted, but forms from a complex set of reactions involving hydrocarbons, oxides of nitrogen, and sunlight (National Research Council 1991). As a result, the spatiotemporal behavior of ground level ozone is depen-

Corresponding author address: Bruce Ainslie, Atmospheric Science Programme, The University of British Columbia, Vancouver, BC V6T 1Z4, Canada.

E-mail:bainslie@eos.ubc.ca dent on the relative rates of ozone production, destruction, advection, and dispersion, with peak concentrations usually occurring in suburban or rural locations, downwind of major emission centers (Sillman 1993). In coastal regions, the redistribution of pollutants, and hence the shape of the ozone plume, is often controlled by either lake (Lennartson and Schwartz 2002) or sea breezes (Lalas et al. 1983). In addition, in complex terrain, with local circulations strongly influenced by small-scale thermal and dynamical processes (Atkinson 1981), pollutant transport is more complex (Horlacher et al. 2000) and the resulting ozone plume shows increased spatial variability (Loibl et al. 1994).

Various methods have been used to investigate the spatiotemporal relationship between ground level ozone and local circulations patterns in coastal regions. Perhaps the most straightforward involves detailed analysis of extensive ozone and meteorological observations. For example, Rosenthal et al. (2003) and Boucouvala and Bornstein (2003) make use of extensive upper-air and surface ozone and meteorological mea-

DOI: 10.1175/JAM2547.1 
surements from the North American Research Strategy for Tropospheric Ozone's (NARSTO) 1997 Southern California Ozone Study (SCOS97) to describe ozone formation and transport in the South Coast Air Basin (SCAB) during a single episode. Rosenthal et al. (2003) show the importance of mesoscale cyclonic eddies and coastal surges in the transport of ozone and its precursors within and out of the SCAB area. Boucouvala and Bornstein (2003) show that the location of maximum ozone concentration during the episode of study coincides with a strong convergence zone caused by onshore sea breeze and valley flows meeting an offshore flow triggered by an unusual upper-level synoptic forcing. Unfortunately, this type of analysis is typically possible only during intensive field campaigns, which themselves span limited time frames.

Where extensive upper-air and surface measurements are not available, model output can be used to supplement observations. For example, Millan et al. (2000) use observations from an extensive network of fixed and temporary field stations, along with mesoscale modeling, to develop a typology of five general diurnal ozone cycles that capture the spatial variability of ozone concentrations in nonurban sites in the Western Mediterranean Basin. A drawback of this approach is the need to run detailed mesoscale models over a sufficiently long time period to capture the most common circulation regimes.

Last, statistical techniques can be used to relate observed spatiotemporal ozone characteristics to observed meteorological conditions. Both Ludwig et al. (1995) and Beaver and Palazoğlu (2006) use an environment-to-circulation approach ${ }^{1}$ to relate local meteorological conditions to spatial ozone concentrations in the San Francisco Bay area. Ludwig et al. (1995) classify patterns of daily maximum ozone concentrations in the San Francisco and Monterey Bay areas, using empirical orthogonal functions (EOFs) and cluster analysis, to find hourly meteorological conditions unique to "exceedances" at the elevated Pinnacles monitoring site in the Monterey Bay area. They show that average ozone patterns from each set of meteorological conditions differ from one another mainly in the location of the peak concentration, from which they infer that the cluster analysis is most sensitive to precursor advection by the local circulation. The high altitude of the Pinnacles site also suggests that some of the observed ozone likely arises from ozone stored in elevated layers,

\footnotetext{
${ }^{1}$ In this type of approach, surface characteristics are first specified and then are related to circulation patterns, whereas in a circulation-to-environment approach, circulation patterns are emphasized to define surface characteristics (Yarnal 1993).
}

which can be transported greater distances aloft than when confined to the boundary layer, implying that a more complete analysis needs to consider variables representing the integrated effects of meteorological conditions over many hours. Beaver and Palazoğlu (2006) perform a two-stage cluster analysis of 8-h-averaged ozone concentrations from a network of 22 San Francisco Bay Area monitoring stations on days when there is an exceedance of the U.S. Environmental Protection Agency (EPA) National Ambient Air Quality Standard (NAAQS). They consider the diurnal influence of meteorological conditions through a comparison of cluster-averaged wind directions and wind speeds for the 24 $\mathrm{h}$ leading up to, and the $24 \mathrm{~h}$ encompassing, each exceedance.

Because most of the day-to-day variability in ozone concentrations can be attributed to changes in meteorological conditions, it is important to perform a clustering analysis using a circulation-to-environment approach. This approach also has the advantage that meteorological observations often have a longer and more complete record than ambient air-quality measurements. Both Davis et al. (1998) and Darby (2005) use a circulation-to-environment approach to study ozone episodes in the Houston, Texas, area, which is a region with a complex coastline but limited topographic relief. Davis et al. (1998) perform a cluster analysis using meteorological data from a single station over 12 AprilOctober periods to find seven distinct meteorological regimes. For each regime, mean hourly ozone concentrations, but not the spatial variability of the ozone plume, are examined. Darby (2005) classifies the circulation around Houston into 16 mesoscale circulation regimes using wind observations from a network of 22 stations. These regimes are used with hourly ozone concentrations to determine the sequence of wind patterns during, and leading up to, hours with high ( $\geq 120 \mathrm{ppb})$ ozone mixing ratios ("concentrations"). The analysis unfortunately spans only a single 27 -day period during the Texas Air Quality Field Study 2000.

In this paper, mesoscale wind regimes in the Lower Fraser Valley (LFV), British Columbia, Canada, a coastal region with complex topography, are examined on days when peak ozone concentrations exceed the Canadian National Ambient Air Quality Objective (NAAQO) of $82 \mathrm{ppb}$ (hourly average). To capture the strong diurnal variation of ozone concentrations, the analysis uses hourly wind measurements taken from two meteorological stations over an entire 24-h period. Twenty years of data are analyzed to capture as many significant mesoscale regimes as possible. Although high ozone concentrations typically occur in the LFV under slack synoptic conditions (Taylor 1992), the re- 
distribution of ozone and its precursors is likely controlled by a combination of mesoscale and synoptic wind patterns. To examine any relationship between mesoscale flow regimes and synoptic-scale forcings, composite synoptic pressure patterns are examined for each flow regime.

Last, because ozone concentrations are dependent on emissions as well as meteorological conditions, the effects of changing emission patterns on the observed ozone plume are also examined. While Vingarzan and Taylor (2003) show a decreasing trend in summertime ozone concentrations at five key measuring stations in the LFV between 1985 and 2000 through the use of a general least squares regression, the interest here lies with ozone concentrations during "exceedance days." From this perspective, Joe et al. (1996) show, by means of a statistical trend detection technique applied to extreme ozone concentrations, that extreme concentrations have increased for stations farthest downwind of the urban Vancouver, British Columbia, Canada, area while those just downwind of the city have decreased. They suggest changes in local emission patterns, stemming from increased up-valley population growth, as a possible cause for this trend. In the Los Angeles, California, area, the apparent eastward shift in its ozone plume is thought to arise from both a reduction in volatile organic compound (VOC)-to-nitrogen oxide $\left(\mathrm{NO}_{x}\right)$ ratio and a change in the spatial population distribution (Schere and Hidy 2000).

\section{Background}

\section{a. Domain}

The LFV, a roughly triangular valley situated on the western coast of North America, spans the CanadaU.S. border along the 49th parallel and has a population of 2.4 million, with the majority living in the city of Vancouver and its surrounding communities. While the valley is relatively flat, it is flanked by the Coast Range (rising to over $2000 \mathrm{~m} \mathrm{MSL}$ ) to the north, the Cascades Ranges (rising to over $1200 \mathrm{~m} \mathrm{MSL}$ ) to the south, the Strait of Georgia to the northwest, and the Juan de Fuca Strait to the southwest (see Fig. 1). In the eastwest direction, the valley narrows from a width of 100 $\mathrm{km}$ at its western edge to a few kilometers at its eastern boundary some $90 \mathrm{~km}$ inland. Several major northsouth-running tributary valleys join the valley to the north.

Once a primarily industrial area, the valley has largely deindustrialized since the 1950s and, as a result, air-quality issues in the valley have changed from smoke and sulfur dioxide $\left(\mathrm{SO}_{2}\right)$ to ozone and fine particulates (Steyn et al. 2005). To protect human health

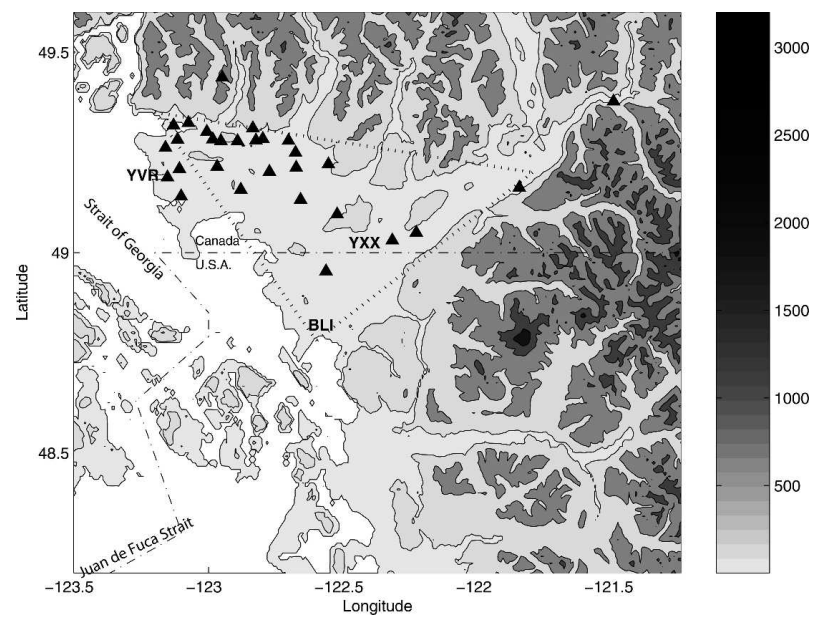

FIG. 1. Topographic relief $(\mathrm{m})$ of the LFV. Also shown are the ozone monitoring stations in operation between 1984 and 2003 (triangles) and the three meteorological stations (YVR, YXX, and BLI) used in the analysis. The dotted line highlights the valley's triangular shape. The southern tip of Vancouver Island, which separates the Strait of Georgia and Juan de Fuca Strait, is visible on the western edge of the domain.

and ecosystems from excessive exposure to ground level ozone, the Canadian Federal Government has defined three thresholds for hourly ambient concentrations-a "desirable" threshold of $52 \mathrm{ppb}$, below which there is no immediate effect on plants and animals; an "acceptable" threshold of $82 \mathrm{ppb}$, below which there is adequate protection for humans and ecosystems; and a "maximum tolerable" threshold of $153 \mathrm{ppb}$, above which immediate action is required to protect human health. Since the 1980s, maximum summertime ozone concentrations in the LFV have steadily decreased, to the point where they seldom exceed the tolerable threshold and on only a few days per year exceed the acceptable limit (Vingarzan and Taylor 2003). This decrease has been achieved despite a $50 \%$ increase in population (Province of British Columbia 2004) and can be credited to a large degree to the following significant reductions in precursor emissions: a $24 \%$ decrease in annual $\mathrm{NO}_{x}$ emissions and a $35 \%$ decrease in VOC emissions (Greater Vancouver Regional District 2003; see Fig. 2).

\section{b. Dataset}

\section{1) Meteorological data}

To classify mesoscale wind regimes, hourly wind speed and direction data from two meteorological station operated by Environment Canada-Vancouver International Airport (YVR) and Abbotsford International Airport (YXX)-were obtained for the $20 \mathrm{yr}$ 


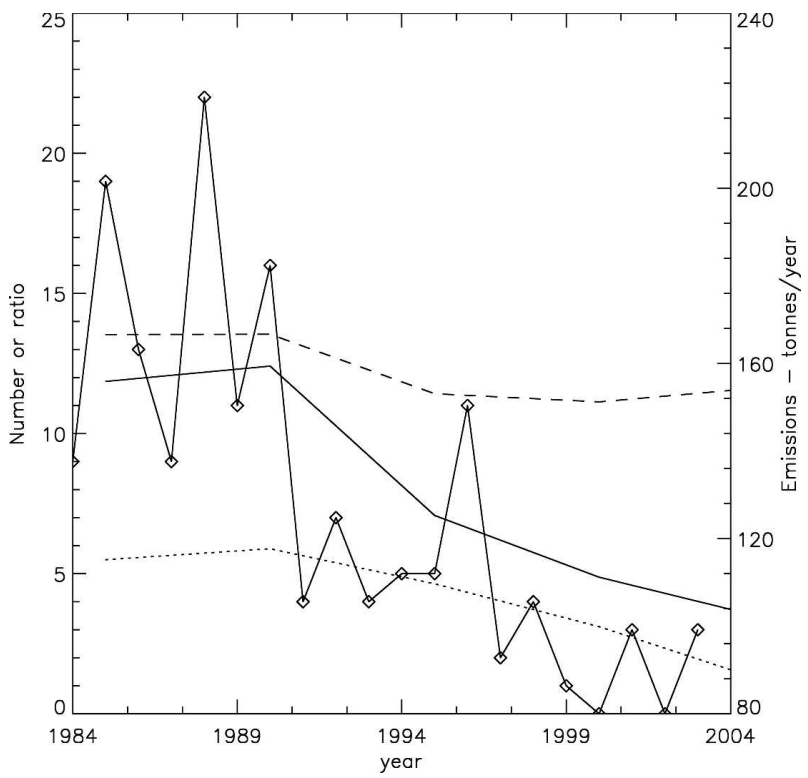

FIG. 2. Number of times one or more stations in the fixed monitoring network records an hourly ozone concentration $>82 \mathrm{ppb}$ (diamonds), annual calculated VOC emissions (solid line), annual calculated $\mathrm{NO}_{x}$ emissions (dotted line), and VOC-to- $\mathrm{NO}_{x}$ ratio based on calculated emissions (dashed line) as a function of year in the LFV.

spanning 1984-2003 (Fig. 1). Hourly wind speed and direction data from the Bellingham International Airport (BLI), operated by the U.S. National Weather Service, were obtained for the 1990-2003 period and were used to determine the influence of an additional measurement station on the results. In addition, YXX hourly temperatures and relative humidities, and YVR hourly rainfall amounts between 1984 and 2003 were obtained.

\section{2) Reanalysis Data}

To complement the mesoscale analysis, synopticscale mean sea level pressure fields were obtained from the European Centre for Medium-Range Weather Forecasts $(\mathrm{ECMWF})$ reanalysis on an $11 \times 6$ grid, extending from $42.5^{\circ}$ to $55^{\circ} \mathrm{N}$ and from $140^{\circ}$ to $115^{\circ} \mathrm{W}$ at a $2.5^{\circ}$ resolution.

\section{3) Ozone data}

Hourly ozone data on the Canadian side of the LFV were obtained from the Greater Vancouver Regional District (GVRD) fixed measuring network. Between 1984 and 2003, ozone has been recorded at 34 different monitoring locations within the network (Fig. 1). At this time, 18 sites monitor ozone, with the network extending east from the downtown core to the eastern- most part of the valley at the town of Hope, British Columbia, Canada. On the U.S. side of the border, hourly data from a single station in Whatcom County at Custer, Washington, were obtained between 1989 and 2003. The hourly ozone dataset was $91.8 \%$ complete, with completeness varying between stations. Furthermore, while many of the stations have been operating in the same locations for the entire 20-yr period, some have undergone slight relocations and others have been closed. No attempt was made to fill in the missing ozone values.

\section{Methods \\ a. Cluster analysis}

Many studies examining mesoscale flow regimes (Weber and Furger 2001; Kastendeuch and Kaufmann 1997; Kaufmann and Weber 1996; Green et al. 1992; Weber and Kaufmann 1995; Kaufmann and Whiteman 1999) employ data from a large number of stations to characterize wind fields in complex terrain. In this study, the interest is not in capturing the entire mesoscale variability of the local wind fields, but rather identifying different mesoscale regimes. From this perspective, data from YVR are used to represent valley-scale winds at the coastline and from YXX for midvalley winds. It is believed that observations from these two stations are sufficient for the identification of mesoscale regimes, because both stations have unobstructed nearfield fetches and are isolated from local topographic features, both have been successfully used to characterize summer and winter sea-breeze regimes in the LFV (Steyn and Faulkner 1986), and the YVR station has been used as a reference for the comparison of hourly wind data from coastal and inland meteorological stations in the LFV (Vasanji and Gartshore 1978). To test the ability of the YVR and YXX stations to capture mesoscale regimes, the data were also reanalyzed with the inclusion of the BLI coastal data over the 19902003 time frame.

Because the interest lies with mesoscale flow regimes on days with high ozone concentrations, an exceedance day is defined as one where at least one station in the fixed monitoring network records an hourly ozone concentration exceeding the 82-ppb acceptable threshold. To select days when high ozone concentrations are caused by local photochemical production, and not by intrusions of stratospheric ozone caused by tropospheric folding (Bovis 2003), either no or low rainfall $(<2.5 \mathrm{~mm}$ measured at YVR) and a maximum temperature at the inland valley station (YXX) of greater than $24.7^{\circ} \mathrm{C}$ are required. This last value was chosen because Burrows et al. (1995) show, using a classifica- 
tion and a regression tree, that high (peak ozone $>40$ $\mathrm{ppb}$ ) and low (peak ozone $<40 \mathrm{ppb}$ ) days in the LFV can be distinguished by this threshold. The observations show 134 days meeting the above requirements between 1984 and 2003. Because the analysis is concerned with the advection and dispersion of anthropogenic emission and subsequent ozone production over a single day, common circulation patterns extending from 0000 to 2300 local standard time (LST) are sought.

From each of the meteorological stations, hourly wind speed and direction data were examined on each exceedance day. The YVR dataset had no missing values, while the YXX dataset had a single missing value that was filled by averaging observations from the two adjacent hours. The BLI dataset was missing $90 \mathrm{~h}$ of data. To fill these missing values, composite hourly $u$ and $v$ wind speeds for the BLI data were developed from the YVR-YXX clustering. Missing BLI values were filled using composite values from the cluster appropriate to the day and hour of the missing value.

To identify mesoscale flow regimes, a two-stage cluster analysis was used on the hourly wind speed and direction data. The data are first clustered using an average within hierarchical clustering technique (Manly 2005 ) on the 24-hourly $u$ and $v$ hourly wind components from the two stations. To allow wind fields with the same wind directions but different wind speeds to be grouped together, each of the 48 wind observations (2 $\times 24$ ) from both stations were replaced by the deviation of that observation from that day's station mean and normalized by that day's station standard deviation. The resulting 96-component wind vectors $(2 \times$ $24 \times 2$ ) from each of the 134 exceedance days were then progressively linked into larger and larger clusters to produce a single hierarchical tree, which is used to determine the number of clusters as well as the starting cluster centroids for the second stage of the analysis. The Euclidean measure of distance between the scaled observations is used in the linking of binary clusters. Following Davis et al. (1998), the distance between two merged clusters is calculated using the average distance between all pairs of objects within clusters. The resulting hierarchical tree showed two large clusters with four smaller and less tightly grouped clusters. A convergent $k$-means analysis (Jain et al. 1999) is then used to minimize within-cluster variance through the reclassification of days. This analysis was seeded with cluster centroids found from the hierarchical clustering.

Each episode day was also classified using the seabreeze filter developed by Steyn and Faulkner (1986) to examine the distribution of sea-breeze days within mesoscale regimes. Also, cluster average surface temperatures and relative humidities at the midvalley were calculated for the $24 \mathrm{~h}$ leading up to, the $24 \mathrm{~h}$ during, and the $24 \mathrm{~h}$ after each exceedance day in order to investigate the extent of inland penetration of marine air for each cluster. Last, because many ozone episodes occur as multiday exceedances, each exceedance day was classified in terms of whether it is the first of a multiday episode, a middle day (neither first nor last), or the last day, or whether it is an isolated, single-day event.

\section{b. Synoptic pressure patterns}

To investigate any link between the mesoscale flow regime and large-scale forcing, composite mean sea level pressure plots, based on ECMWF reanalysis valid at 1200 UTC (0400 LST) on each exceedance day, were calculated for each cluster using a $12.5^{\circ} \times 25^{\circ}$ grid over the Pacific Northwest. This grid was suggested by McKendry (1994) as a suitable domain for capturing weather patterns associated with ozone episodes in the LFV.

\section{c. Temporal variability}

Figure 2 shows that the frequency of network-resolved exceedances has dropped between 1984 and 2003. To see if this drop has occurred equally for all mesoscale flow regimes, the proportion of fair-weather summer days between 1984 and 2003 that are exceedance days is calculated. The definition of a fair-weather summer day is chosen to be consistent with the exceedance day definition, namely, an April-September day where the maximum midvalley temperature at YXX exceeds $24.7^{\circ} \mathrm{C}$ and YVR rainfall is less than $2.5 \mathrm{~mm}$. Each of these days was then allocated to one of the clusters using the 24-hourly YVR wind observations. Last, the percent of fair-weather days that are also episode days is calculated for each cluster.

\section{d. Spatial ozone distribution}

To investigate how changes in the region's emissions may have influenced the spatial distribution of ozone on exceedance days, for each cluster composite ozone patterns taken at the hour of the peak ozone concentration were examined using a proportional symbol plot. Because the LFV has also seen a general decrease in peak concentrations on episode days, in addition to a general decrease in the average number of exceedance days per year, in order to examine the spatial structure of the ozone plume, standardized ozone values were used in the spatial analysis. In this way, before averaging, observations were first transformed by subtracting the network mean (at the hour of the maximum obser- 
vation) from each observation and scaling the residual by the hour's standard deviation. The standardized values ( $z$ values) for every day in each cluster were then averaged together and the resulting average values were plotted at each station using markers proportional to the station's average $z$ value.

Last, to see how emissions reductions and changes in emission patterns may have altered the ozone plume on exceedance days, for each exceedance day, the eastwest $\left(X_{c}\right)$ and north-south $\left(Y_{c}\right)$ components of the observed ozone plume's centroid,

$$
\begin{aligned}
X_{c} & =\frac{\sum \mathrm{utmx}_{i} \times\left[\left(\mathrm{O}_{3}\right)_{i}-\left(\mathrm{O}_{3}\right)_{o}\right]}{\sum\left[\left(\mathrm{O}_{3}\right)_{i}-\left(\mathrm{O}_{3}\right)_{o}\right]} \text { and } \\
Y_{c} & =\frac{\sum \mathrm{utmy}_{i} \times\left[\left(\mathrm{O}_{3}\right)_{i}-\left(\mathrm{O}_{3}\right)_{o}\right]}{\sum\left[\left(\mathrm{O}_{3}\right)_{i}-\left(\mathrm{O}_{3}\right)_{o}\right]}
\end{aligned}
$$

were calculated, where utmx ${ }_{i}$ and $\mathrm{utmy}_{i}$ are the universal transverse Mercator (UTM) easting and northing for the $i$ th monitoring station. Only the portion of the ozone plume $\left[\left(\mathrm{O}_{3}\right)_{i}\right]$ for which concentrations are higher than a background level $\left[\left(\mathrm{O}_{3}\right)_{o}\right]$ chosen to be either 52 (equivalent to the NAAQO 1-h desirable level) or 32 (typical of mean summertime concentrations in the LFV; Vingarzan and Taylor 2003) ppb were examined. Because these values are arbitrary, the analysis considers both background values. A linear regression was then performed using the center of mass and the number of days that have passed between 1 April 1984 and the day of the exceedance $(t)$ :

$$
\begin{aligned}
& X_{c}=\alpha+\beta t \quad \text { and } \\
& Y_{c}=\alpha+\beta t
\end{aligned}
$$

to see if there has been a shift in the ozone plume centroid over the last $20 \mathrm{yr}$. To test the validity of the linear regression, all model residuals were checked for normality using Q-Q plots and the Jarque-Bera test for normality (Jarque and Bera 1980). In addition, regression residuals were plotted against the observed centroid positions to check for nonconstant residual variance. It must be emphasized that this regression analysis is intended only to demonstrate the existence of a spatiotemporal trend in the ozone plume over the analysis period. The analysis does not imply any process-based meaning to the $\alpha$ and $\beta$ regression coefficients.

\section{Results}

\section{a. Mesoscale wind regimes}

Cluster solutions using from four to eight clusters were investigated, and it was found that the four-cluster solution provided the highest global within-group similarity without producing clusters with few members. In Fig. 3, composite hodographs from the YVR station for each cluster (based on the original, not the standardized observations) are plotted. The size of the cross at the origin of each hodograph gives the $u$ and $v$ wind component standard deviations. The four clusters can be viewed as subclasses of two broad classes-those with northwesterly daytime winds (clusters I and II) and those with a southerly component to the daytime winds (clusters III and IV). Cluster I shows greater variability in daytime wind direction and has higher morning wind speeds than cluster II, while cluster IV has a much more pronounced nighttime easterly wind component than cluster III.

Only $7.5 \%$ of exceedances in cluster I have a welldeveloped sea breeze, and only $5.7 \%$ of the exceedances cluster II do (see Table 1). High frequencies of sea-breeze circulations occurs with cluster III $(65.7 \%)$ and IV (33.3\%), with cluster III having a composite hodograph similar to the sea-breeze composite YVR hodograph produced by Steyn and Faulkner (1986) for summer days between 1973 and 1982.

The distribution of these days by cluster, given in Table 1, shows cluster IV is always the last day of an episode (i.e., it is never the first or middle day in a multiday episode). Further examination of Table 1 shows that cluster III, the cluster most closely associated with a pure sea-breeze day, most often either occurs on its own $(51.4 \%)$ or marks the onset of a multiday episode $(25.7 \%)$, but rarely appears the last day $(8.6 \%)$. Correspondingly, cluster II, with a hodograph similar to III but with more northerly winds, is most likely to be found at the start of an episode $(42.9 \%)$ and not at the end $(14.2 \%)$. Cluster I is most often found ending a multiday episode $(40.0 \%)$, but is reasonably well distributed among the other categories.

Hodographs from YXX (not shown) exhibit strong topographic constraining; each has the wind direction aligned with the orientation of the valley, similar to the composite YXX hodographs in Steyn and Faulkner (1986). The main distinction between the YXX hodographs is given by the magnitude of the afternoon wind speeds with clusters II and IV having the highest speeds while clusters I and III have the lowest.

\section{b. Composite synoptic pressure patterns over the Pacific Northwest}

By early afternoon, all clusters show wind direction becoming onshore, likely in response to greater surface heating over the valley than the ocean. On the other hand, the two principal morning wind directions 

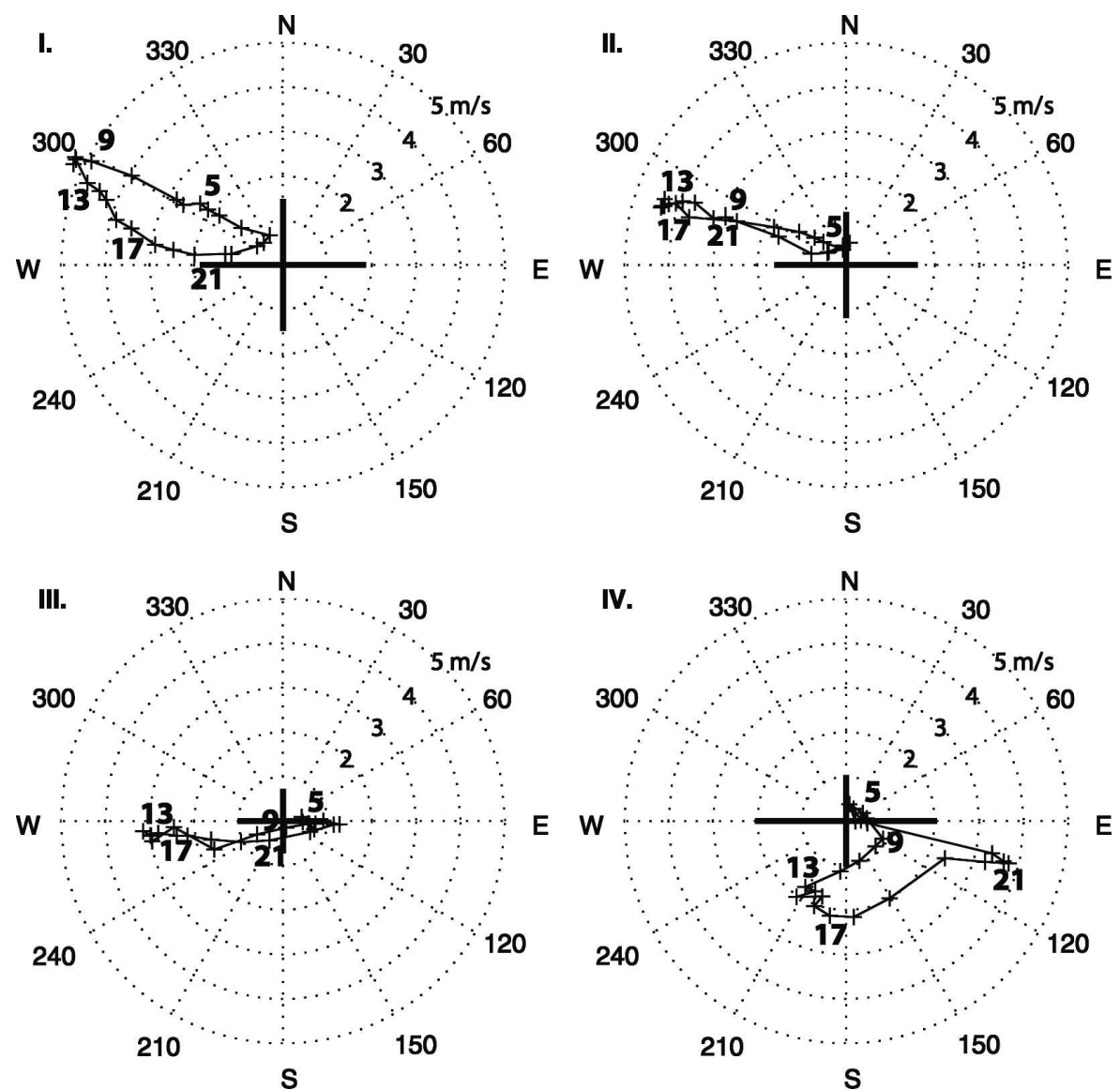

FIG. 3. Composite YVR hodographs using the original wind and not the standardized values $(z$ values) for clusters (top left) I, (top right) II, (bottom left) III, and (bottom right) IV. The arms of the cross at the origin give the size of the average std dev of $u$ and $v$ wind components, respectively. Boldface numbers indicate time (UTC).

[westerly (I and II) and southerly (III and IV)] suggest channeling by the coastal mountains and Vancouver Island to produce flows that originate either from the Strait of Georgia or the Juan de Fuca Strait (Lange 1998).

In Fig. 4, composite plots of mean sea level pressure for each cluster are given. All plots show a northerly extension of the subtropical Pacific high over the eastern Pacific Ocean, with a shallow thermal trough over southwestern North America extending northward into British Columbia. These composite pressure patterns, consistent with McKendry's (1994) Kirchhofer analysis (which associates synoptic pressure patterns having a thermal trough with high summertime ozone concentrations), highlight the limited synoptic variability during ozone exceedances in the LFV. Nonetheless, there are important differences in the pressure patterns.

Clusters I and II, both with YVR morning winds from the northwest, have the thermal trough extending to the northern tip of Vancouver Island producing a strong pressure gradient between that location and Vancouver. This pressure pattern enables winds traveling down the Strait of Georgia to reach Vancouver in the morning, while clusters III and IV, with pressure patterns showing little pressure difference over Vancouver Island, allow winds from the Juan de Fuca Strait to reach Vancouver from the south in the morning. The slack pressure gradients for these clusters fa-

TABLE 1. Number of exceedance days, their percentage with well-defined sea breezes, their percentage as the first, last, and middle day in multiday episodes, and their percentage as singleday episode, for each cluster.

\begin{tabular}{lccrrrr}
\hline \hline Cluster & Days & Sea breeze & First & Last & Middle & Single \\
\hline I & 47 & 7.5 & 27.5 & 40.0 & 20.0 & 12.5 \\
II & 32 & 5.7 & 42.9 & 11.4 & 31.4 & 14.2 \\
III & 32 & 65.7 & 25.7 & 8.6 & 14.3 & 51.4 \\
IV & 24 & 33.3 & 0.0 & 66.7 & 0.0 & 33.3 \\
\hline
\end{tabular}


Cluster I.

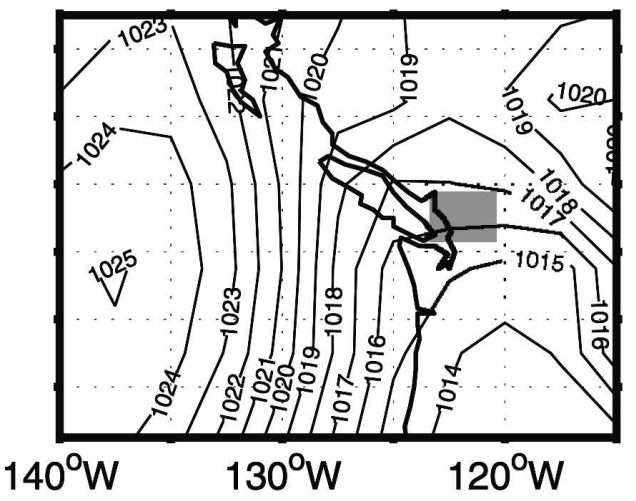

Cluster III.

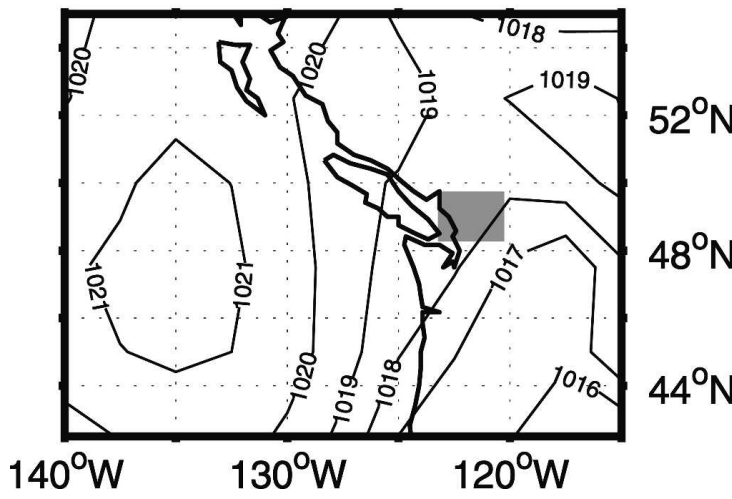

Cluster II.

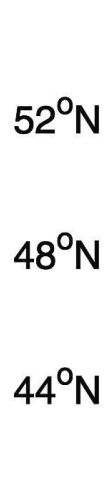

$140^{\circ} \mathrm{W}$

$52^{\circ} \mathrm{N}$

$48^{\circ} \mathrm{N}$

$44^{\circ} \mathrm{N}$

$52^{\circ} \mathrm{N}$

$48^{\circ} \mathrm{N}$

$44^{\circ} \mathrm{N}$

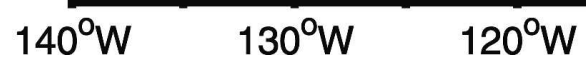

FIG. 4. Composite synoptic mean sea level pressure patterns (hPa) for clusters (top left) I, (top right) II, (bottom left) III, and (bottom right) IV. Shaded area gives spatial extent of the LFV as defined in Fig. 1.

cilitate the development of sea-breeze circulations as shown by the high sea-breeze frequency for these clusters.

\section{c. Composite spatial ozone patterns for the mesoscale clusters}

In Fig. 5 proportional symbol plots of the standardized ozone concentrations for each station and for each cluster are plotted. All show the lowest concentrations in and around the Vancouver area, reflecting ozone titration from fresh $\mathrm{NO}_{x}$ emissions, with concentrations increasing up-valley. Clusters I, II, and III have their highest concentrations at the most northeastern station (situated in the town of Hope). All of these clusters have hodographs with morning coastal onshore flows. However, cluster III, with its southerly component to the onshore flow and generally lighter winds, shows higher midvalley ozone values than either clusters I or II. Cluster IV, with its light southwest coastal winds throughout the day, shows its highest ozone values in midvalley.

\section{d. Decadal variability of the ozone plume}

To see the impacts of mesoscale flow regimes and emission reductions on exceedance days, Fig. 6a shows the percent of summer days that is fair weather, and in Fig. $6 \mathrm{~b}$ the percent of these fair-weather days that are also exceedance days is plotted for each regime. The percent of fair-weather summer days shows year-toyear variability but no long-term trend, while the percent of fair-weather days that are exceedance days shows a generally decreasing trend for each cluster. To the extent that the fair-weather filter does not miss any unseen meteorological conditions that may be influencing ozone formation, from the figure it can be inferred that the (calculated) emission reductions over the last $20 \mathrm{yr}$ (cf. Fig. 2) have lead to a decreased likelihood of ozone exceedances for all flow regimes, although there is a great year-to-year variability. These results are consistent with the decreasing trend in summertime ozone concentrations in the LFV observed by Vingarzan and Taylor (2003) and the large decrease in ozone concentrations observed during two ozone episodes-one in 

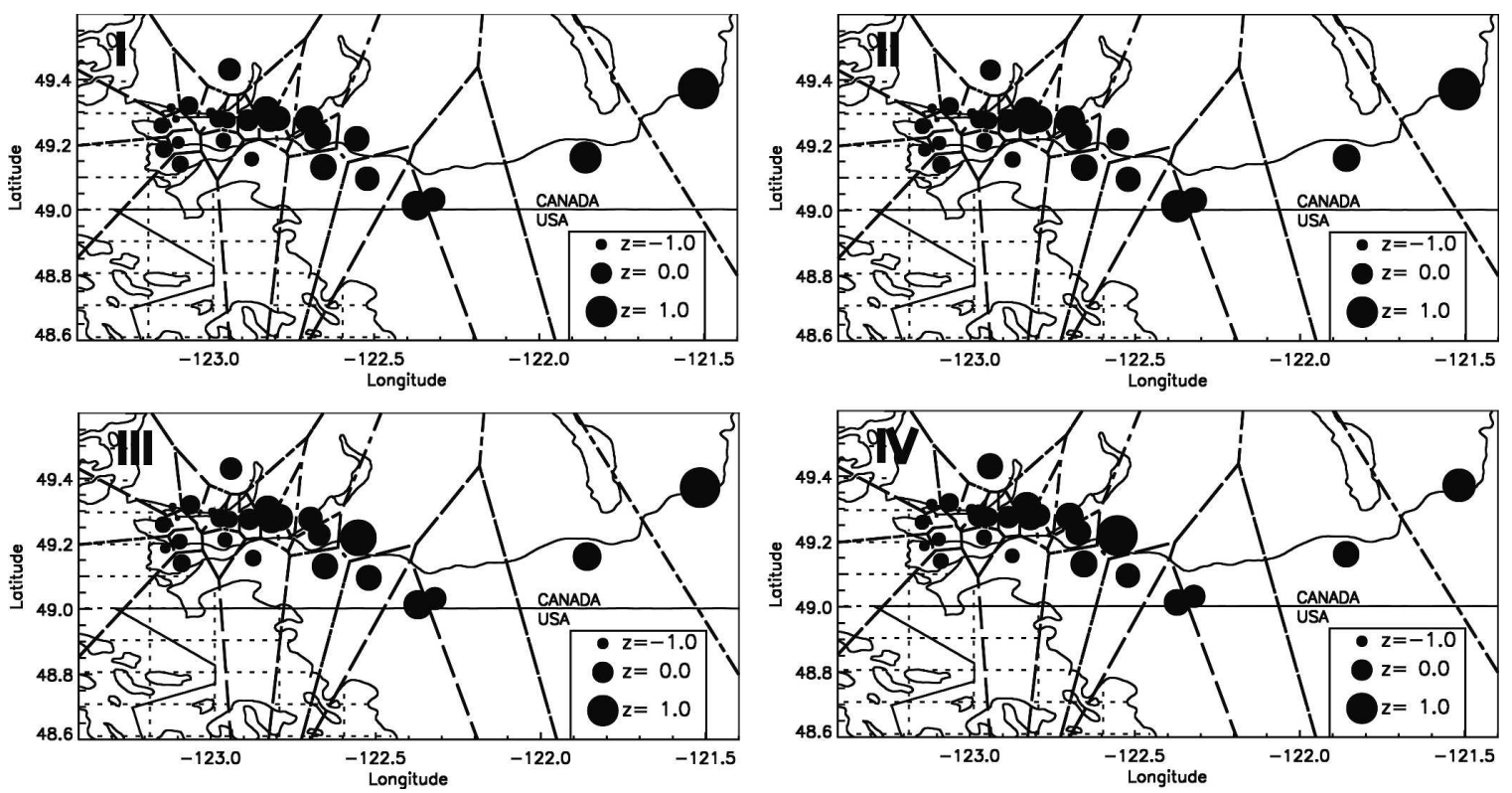

FIG. 5. Proportional symbol plot for composite ozone values at the fixed monitoring stations in the LFV for clusters (top left) I, (top right) II, (bottom left) III, and (bottom right) IV. The network includes all stations that have monitored hourly ozone concentrations between 1984 and 2003. In the case in which a station has moved locations, its average position is used. Ozone values are reported in standardized values $(z$ values with $z=-1.0,0.0$, and +1.0$)$. Also shown are Voronoi polygons surrounding each station (dash-dot lines), coastlines, U.S.-Canada border, major rivers, and lakes (solid lines). The dotted latitude and longitude lines cover the ocean portions of the figure.

1988 and the other in 1999-having essentially identical synoptic and mesoscale meteorological conditions (Steyn et al. 1999).

\section{e. Temporal variability of plume centroid position}

In Fig. 7 the east-west and north-south centroid coordinates for both the 32- and 52-ppb background ozone concentrations are plotted (east-west coordinates w.r.t. the westernmost monitoring station and north-south coordinates w.r.t. the southernmost station). For both background concentrations, the eastwest plume centroid position shows year-to-year variability but appears to show a westward shift up until the late 1980s, and then an eastward shift thereafter. To further examine this, the following two separate linear regressions on the plume centroid were performed: one for 1984-89 and another for 1990-2003. While the choice of division point is arbitrary, note that in Fig. 2 the number of ozone episodes, the total amount of VOC and $\mathrm{NO}_{x}$ emissions, and the VOC-to- $\mathrm{NO}_{x}$ ratio all show a noticeable decrease at that time. Thus, there is some reason to believe the ozone plume may have changed behavior at that time. In addition, because the easternmost measuring station at Hope was only added to the network in the summer of 1991, its readings were excluded from the analysis. This was done to prevent this additional eastern station from artificially influencing any east-west shift.

In each figure, the two least squares regression lines for the 1984-89 and 1990-2003 periods have been plotted. Regression results are given in Table 2. For both background levels, the $X_{c}$ linear temporal dependence shows a statistically significant negative trend for 1984 90 and a positive trend during the remaining years (Table 2), implying that the center of mass initially moved westward before undergoing an eastward shift. For $Y_{c}$, the analysis shows a smaller but still statistically significant southward shift in the plume for the 19902003 period. The north-south centroid changes are not significant in the earlier era.

\section{Discussion}

While the clustering analysis has identified different mesoscale flow regimes on exceedance days based on wind measurements from two meteorological stations and found the associated synoptic pressure patterns with each regime to share common features, it is likely that part of the mesoscale variability arises from smallscale pressure differences, influenced by local topography, land use, and insolation that is not evident at the synoptic scale. Regardless of mechanism causing the 

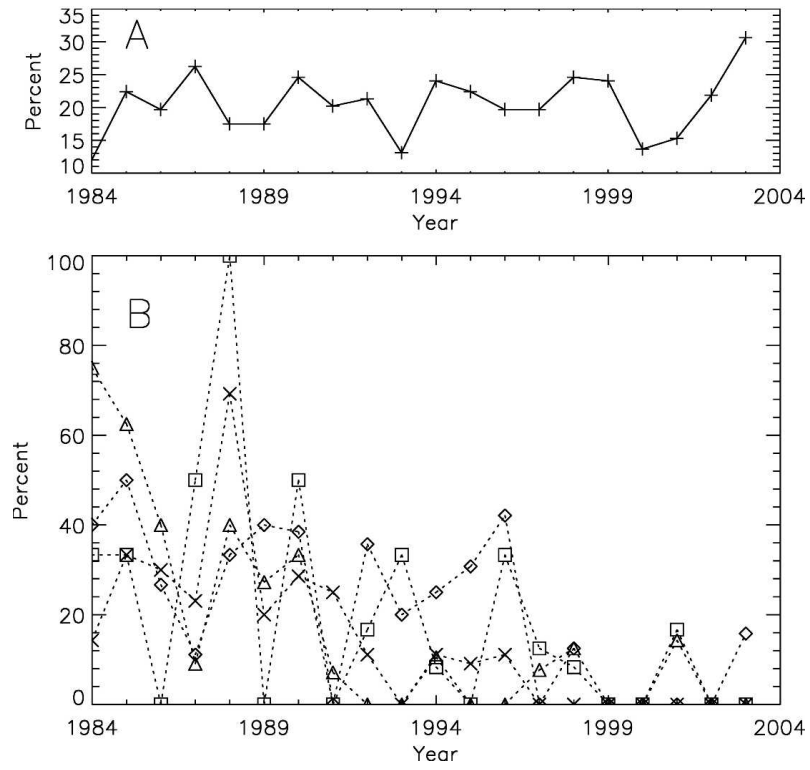

FIG. 6. (a) Percent of summer days that are fair-weather days and (b) percent of fair-weather days for each mesoscale regime (cluster I $\rightarrow$ diamonds, II $\rightarrow$ crosses, III $\rightarrow$ triangles, and IV $\rightarrow$ squares) that are exceedance days as a function of year. variability, inspection of the composite hodographs in Fig. 3 shows the mesoscale regimes differ the most in the morning hours, coincident with the large release of precursor emissions during the morning rush hour. This has important implications for the numerical modeling of ozone formation and suggests that capturing the onset of thermally driven circulations in the morning hours will be critical in predicting peak ozone concentrations. The clustering analysis has also been performed using observations from YVR, YXX, and BLI over the 1990-2003 period. This analysis, with its additional station, produces results similar to the clustering presented here but with more variability, likely due to the fewer exceedance days (58) in the 1990-2003 analysis period.

The examination of exceedance days by their occurrence in multiday episodes shows that clusters I and IV are associated with the ending of episodes. With many LFV ozone episodes ending when the upper-level ridge shifts eastward, allowing the incursion of cool marine air from the eastern Pacific into the Juan de Fuca Strait (locally referred to as a "marine push" or "stratus
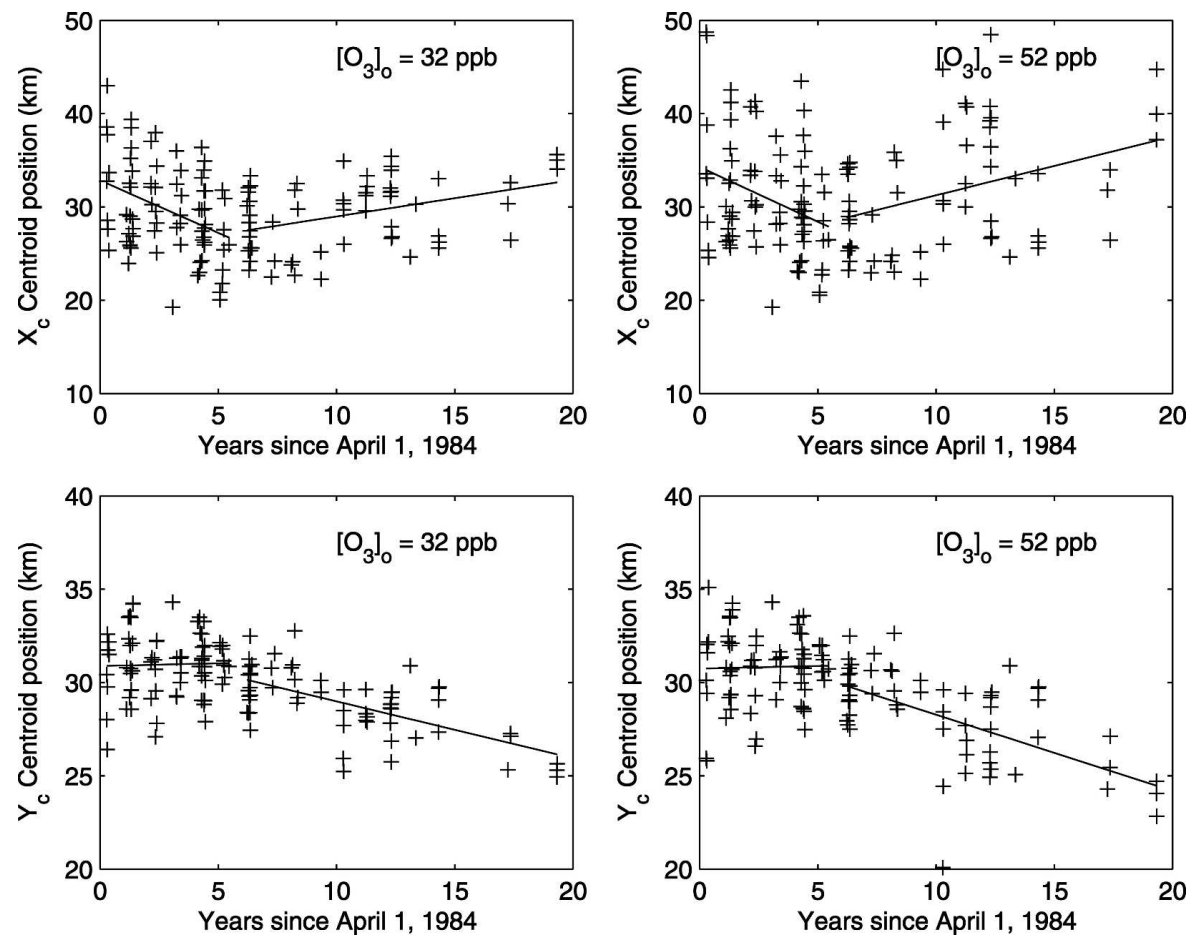

FIG. 7. Plume centroid coordinates as a function of elapsed time since 1 Apr 1984 in both (top) the east-west $\left(X_{c}\right)$ and (bottom) the north-south $\left(Y_{c}\right)$ direction and for both a (left) 32- and (right) 52-ppb background ozone concentration. Coordinates are relative to the LFV's westernand southernmost monitoring stations. Also plotted on each figure are the two linear regression models for the 1984-89 and the 1990-2003 periods (solid lines). East-west distances are with respect to the western edge of the fixed monitoring network, and north-south distances are with respect to the network's southern edge. 
TABLE 2. Coefficients $(\alpha$ and $\beta)$ from the linear regression for both the east-west $\left(X_{c}\right)$ and north-south $\left(Y_{c}\right)$ center of mass using background concentrations of 32 and $52 \mathrm{ppb}$. East-west distances are relative to the westernmost station, and north-south distances are relative to the southernmost station. Also given are calculated $F$ statistics, which can be compared with the critical $F$ values of 3.97 (75 observations for the years 1984-89) and 4.01 (58 observations for the years 1990-2003).

\begin{tabular}{|c|c|c|c|c|c|c|}
\hline \multirow[b]{2}{*}{ Years } & \multicolumn{3}{|c|}{$X_{c}$} & \multicolumn{3}{|c|}{$Y_{c}$} \\
\hline & $\begin{array}{c}\alpha \\
(\mathrm{km})\end{array}$ & $\begin{array}{c}\beta \\
\left(\mathrm{km} \mathrm{yr}^{-1}\right)\end{array}$ & $\begin{array}{c}F \\
\text { value }\end{array}$ & $\begin{array}{c}\alpha \\
(\mathrm{km})\end{array}$ & $\begin{array}{c}\beta \\
\left(\mathrm{km} \mathrm{yr}^{-1}\right)\end{array}$ & $\begin{array}{c}F \\
\text { value }\end{array}$ \\
\hline \multicolumn{7}{|c|}{$\left(\mathrm{O}_{3}\right)_{o}=32 \mathrm{ppb}$} \\
\hline 1984-89 & 32.8 & -1.12 & 11.7 & 30.9 & 0.029 & 0.06 \\
\hline 1990-2003 & 25.1 & 0.39 & 10.5 & 32.4 & -0.30 & 39.1 \\
\hline \multicolumn{7}{|c|}{$\left(\mathrm{O}_{3}\right)_{o}=52 \mathrm{ppb}$} \\
\hline 1984-89 & 34.3 & -1.18 & 7.5 & 30.7 & 0.030 & 0.05 \\
\hline $1990-2003$ & 24.9 & 0.63 & 9.2 & 32.4 & -0.41 & 27.1 \\
\hline
\end{tabular}

surge"; Lange 2003) it is likely that cluster IV, with its southerly winds, captures some of this behavior. This assertion is strengthened through an examination of cluster-averaged surface temperatures at YXX for the $24 \mathrm{~h}$ leading up to, the $24 \mathrm{~h}$ during, and $24 \mathrm{~h}$ following each exceedance day (Fig. 8). The figure shows that days following cluster-IV exceedances have a greater reduction in peak temperatures than the other clusters, consistent with incursion of cool marine air. Also, cluster IV has the highest daytime relative humidity during, and for the $24 \mathrm{~h}$ following, each exceedance day (not shown). It is interesting to note that the observed marine push on 5-6 August 1993 (Pottier et al. 1997), which ended the ozone episode during the LFV Pacific 1993 field campaign (Steyn et al. 1997), was allocated to cluster IV. The association of cluster I with the end of an ozone episode is less clear than with cluster IV, although its stronger synoptic pressure gradients (Fig. 4) and higher morning coastal winds (Fig. 3) suggest a transition day away from the stagnant conditions typical of exceedance days.

The similarities between each cluster's composite ozone spatial distribution (cf. Fig. 5) suggests that the influence of precursor buildup and other handover processes (McKendry and Lundgren 2000) leading up to an ozone episode may be more important than the mesoscale circulation patterns. This lack of dominant meteorological influence may also be related to the region's modest emissions rates, which force elevated ozone concentrations to occur under relatively extreme and infrequent conditions.

The apparent lack of strong meteorological influence on the episodic ozone plume also justifies the grouping of all clusters together in the centroid analysis and suggests that any temporal change in the observed plume centroid should largely be driven by emissions changes. This is consistent with the centroid analysis, which shows an abrupt change in centroid position coincident with the noticeable changes in the region's emissions inventory in 1989-90. It appears that the plume centroid has moved generally eastward since 1990. It is not possible to tell if this shift is due to changes to the ratio of VOC-to- $\mathrm{NO}_{x}$ emissions or to increased urban development up-valley. The apparent southward shift in the plume is likely due to the slight north-south alignment of the coastal mountains forcing the plume southward as it shifts up-valley.

Another reason for the lack of spatial variability in the composite ozone patterns may stem from the layout of the fixed monitoring network. The Voronoi polygons around the stations in Fig. 5 reveal a network bias with more stations close to the urban core, and fewer upvalley and almost no stations away from the valley axis in the north-south direction. As a result, the network may not be able to capture significant portions of the ozone plume, which is a possibility supported by research that shows measured ozone concentrations in some of the LFV's northern tributary valleys, which are equal to or exceed those measured in the LFV (McKendry et al. 1998a,b), and modeled ozone fields, which show an ozone plume with two distinct peaks in the mountains to the north and southeast of the LFV Hedley and Singleton (1997). Thus, a more complete description of the interplay between emissions and local circulation regimes is difficult to develop given the current spatial distribution of measuring stations, but this could be improved through further field measurements, the spatial interpolation of station observations through a cokriging analysis using hourly temperatures measurements taken from additional meteorological, forestry, and highway stations (Frązek et al. 2003), and by means of Eulerian grid model output, an approach that is currently under way.

\section{Conclusions}

The spatiotemporal dependence of ground level ozone on local circulation patterns in the LFV, an urban coastal region with complex topography over a 20yr period, has been examined. In a novel approach to classifying wind regimes, observations over a $24-\mathrm{h}$ period have been used in order to capture the interdependence of precursor advection and photochemical production in generating the resulting ozone field. By means of a cluster analysis using $20 \mathrm{yr}$ of meteorological data from two stations, drawn from days when hourly ozone concentrations exceed the NAAQO "acceptable" threshold of $82 \mathrm{ppb}$, four mesoscale circulation 

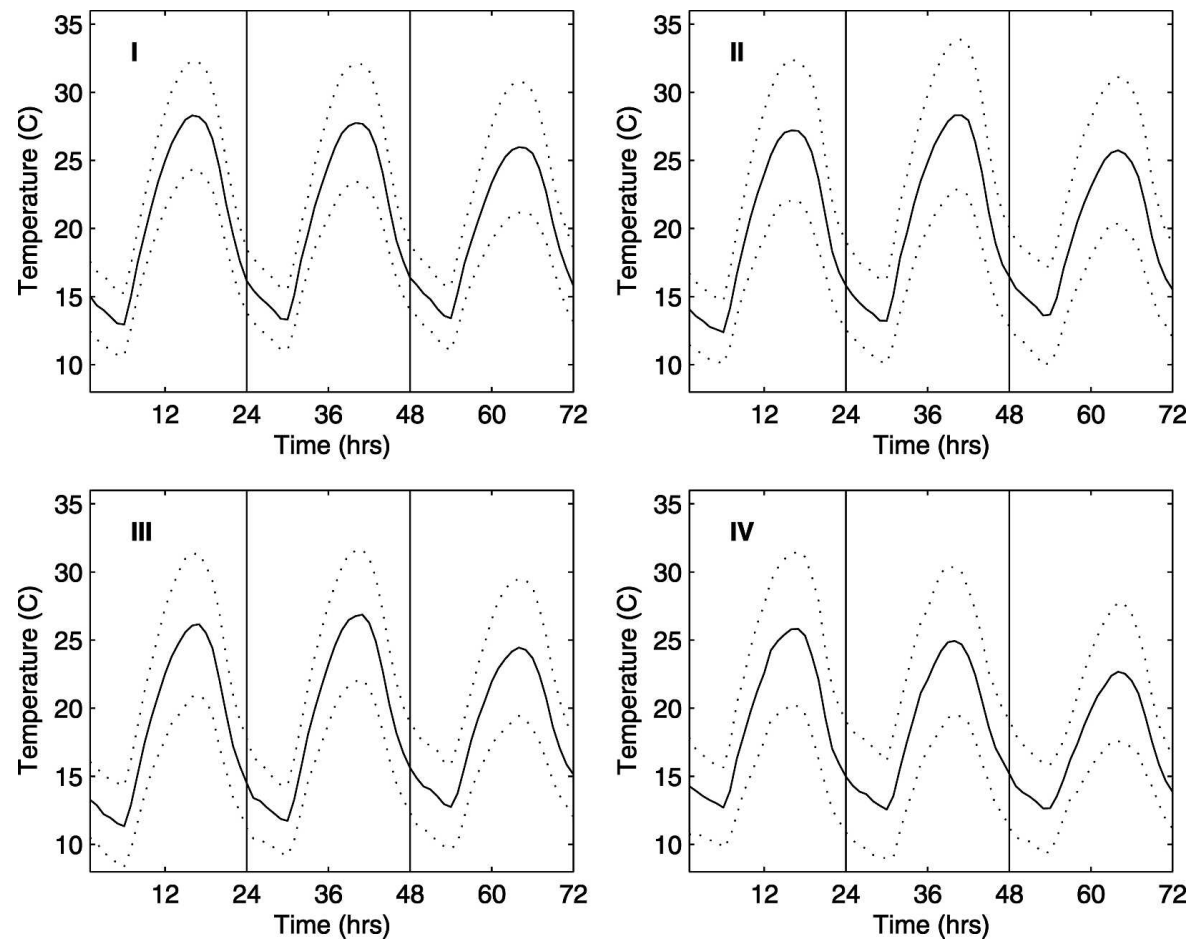

FIG. 8. Cluster-averaged hourly temperatures (solid lines) at YXX for the $24 \mathrm{~h}$ leading up to, the $24 \mathrm{~h}$ during, and the $24 \mathrm{~h}$ following each episode for clusters (top left) I, (top right) II, (bottom left) III, and (bottom right) IV. The dotted lines are plotted at \pm 1 std dev around the averages.

regimes have been identified. The small number of clusters obtained in the analysis reflects the limited range of synoptic conditions associated with high ozone concentrations and the topographic constraints imposed on the mesoscale circulations under these meteorological conditions. The four regimes can be viewed as subclasses of two broad classes dependent on the morning wind direction at the coastal YVR meteorological station. It is also found that exceedance days are not associated with a well-defined sea-breeze circulation, with sea-breeze frequency varying between regimes. While the analysis only considers wind patterns over a 24-h period, it is likely that some of the plume spatial variability is influenced by pollutant carryover from previous days (McKendry 1994; Burrows et al. 1995).

As the population of an urban area grows, emissions sources change in type, amount and location. These affect the spatial variability of the resulting ozone plume in a complex way, and the cluster analysis has been used to investigate how the LFV ozone plume has evolved in response to changes in local emission patterns. Coincident with noticeable emissions reductions, achieved partly through the region's air-quality management plan (Greater Vancouver Regional District 1994), the proportion of fair-weather days, which have exceedance level ozone concentrations, has decreased for each regime over the last $20 \mathrm{yr}$, but with large yearto-year variability. Last, the centroid of the ozone plume appears to have shifted eastward, likely in response to either or both an increase in development up-valley and/or a large decrease in the VOC-to- $\mathrm{NO}_{x}$ ratio of the region's emissions inventory.

Acknowledgments. Funding for this research was through the National Science and Engineering Research Council (NSERC) and the Canadian Foundation for Climate and Atmospheric Sciences (CFCAS). Special thanks are given to Pat Wong at Environment Canada for assistance with some of the meteorological data and to Drs. Ian McKendry and Jim Zidek for their helpful comments.

\section{REFERENCES}

Abraham, J. S., and A. C. Comrie, 2004: Real-time ozone mapping using a regression-interpolation hybrid approach, applied to Tucson, Arizona. J. Air Waste Manage. Assoc., 54, 914-925.

Atkinson, B. W., 1981: Meso-scale Atmospheric Circulations. Academic Press, 495 pp.

Beaver, S., and A. Palazoğlu, 2006: A cluster aggregation scheme for ozone episode selection in the San Francisco, CA Bay Area. Atmos. Environ., 40, 713-725.

Boucouvala, D., and R. Bornstein, 2003: Analysis of transport 
patterns during a SCOS97-NARSTO episode. Atmos. Environ., 37 (Suppl. 2), S73-S94.

Bovis, P. E., 2003: Stratosphere troposphere exchange and its influence on surface ozone concentrations in the Lower Fraser Valley. Master's thesis, Dept. of Earth and Ocean Sciences, University of British Columbia, $120 \mathrm{pp}$.

Burrows, W. R., M. Benjamin, S. Beauchamp, E. L. Lord, D. McCollor, and B. Thomson, 1995: CART decision-tree statistical analysis and prediction of summer season maximum surface ozone for the Vancouver, Montreal, and Atlantic regions of Canada. J. Appl. Meteor., 34, 1848-1862.

Darby, L. S., 2005: Cluster analysis of surface winds in Houston, Texas, and the impact of wind patterns on ozone. J. Appl. Meteor., 44, 1788-1806.

Davis, J. M., B. K. Eder, D. Nychka, and Q. Yang, 1998: Modeling the effects of meteorology on ozone in Houston using clustering analysis and generalized additive models. Atmos. Environ., 32, 2505-2520.

Frązek, W., A. Bytnerowicz, and M. J. Arbaugh, 2003: Use of geostatistics to estimate surface ozone patterns. Ozone Air Pollution in the Sierra Nevada: Distribution and Effects on Forests, W. Frazek et al., Eds., Elsevier, 215-247.

Greater Vancouver Regional District, 1994: GVRD air quality management plan. GVRD Policy and Planning Department Tech. Rep., 42 pp.

— 2003: Forecast and backcast of the 2000 emissions inventory for the Lower Fraser Valley airshed 1985-2025. GVRD Policy and Planning Department Tech. Rep., Burnaby, BC, Canada, 95 pp.

Green, M. C., L. O. Myrup, and R. G. Flocchini, 1992: A method for classification of wind field patterns and its application to southern California. Int. J. Climatol., 12, 111-135.

Hedley, M., and D. L. Singleton, 1997: Evaluation of an air quality simulation of the Lower Fraser Valley. I. Meteorology. Atmos. Environ., 31, 1605-1615.

Horlacher, K. V., U. Corsmeier, A. Volz-Thomas, B. Kolahgar, H. Gei, M. Möllmann-Coers, and A. Knaps, 2000: Influence of valley winds on transport and dispersion of airborne pollutants in the Freiburg-Schauinsland area. J. Geophys. Res., 105, $1585-1597$

Jain, A. K., M. N. Murty, and P. J. Flynn, 1999: Data clustering: A review. ACM Comput. Surv., 31, 264-323.

Jarque, C. M., and A. K. Bera, 1980: Efficient tests for normality, homoscedasticity and serial independence of regression residuals. Econ. Lett., 6, 255-259.

Joe, H., D. G. Steyn, and E. Susko, 1996: Analysis of trends in tropospheric ozone in the Lower Fraser Valley, British Columbia. Atmos. Environ., 30, 3413-3421.

Kastendeuch, P. P., and P. Kaufmann, 1997: Classification of summer wind fields over complex terrain. Int. J. Climatol., 17, $521-534$.

Kaufmann, P., and R. O. Weber, 1996: Classification of mesoscale wind fields in the MISTRAL field experiment. J. Appl. Meteor., 35, 1963-1979.

— wintertime wind patterns in the Grand Canyon region. $J$. Appl. Meteor., 38, 1131-1147.

Lalas, D. P., D. Asimakopoulos, D. G. Deligiorgi, and C. G. Helmis, 1983: Sea-breeze circulation and photochemical pollution in Athens, Greece. Atmos. Environ., 17, 1621-1632.

Lange, O. S., 1998: The Wind Came All Ways: A Quest to Understand the Winds, Waves and Weather in the Georgia Basin. Environment Canada, 123 pp.
- 2003: Living with Weather along the British Columbia Coast: The Veil of Chaos. Environment Canada, 198 pp.

Lennartson, G. J., and M. D. Schwartz, 2002: The lake breezeground-level ozone connection in eastern Wisconsin: A climatological perspective. Int. J. Climatol., 22, 1347-1364.

Loibl, W., W. Winiwarter, A. Kopsca, J. Zueger, and R. Baumann, 1994: Estimating the spatial distribution of ozone concentrations in complex terrain. Atmos. Environ., 28, 25572566.

Ludwig, F. L., J.-Y. Jiang, and J. Chen, 1995: Classification of ozone and weather patterns associated with high ozone concentrations in the San Francisco and Monterey Bay area. Atmos. Environ., 29, 2915-2928.

Manly, B. F. J., 2005: Multivariate Statistical Methods: A Primer. 3d ed. Chapman \& Hall, 214 pp.

McKendry, I. G., 1994: Synoptic circulation and summertime ground-level ozone concentrations at Vancouver, British Columbia. J. Appl. Meteor., 33, 627-641.

- , and J. Lundgren, 2000: Tropospheric layering of ozone in regions of urbanized complex and/or coastal terrain: A review. Prog. Phys. Geogr., 24, 329-354.

- D. G. Steyn, R. M. Banta, W. Strapp, K. Anlauf, and J. Pottier, 1998a: Daytime photochemical pollutant transport over a tributary valley lake in southwestern British Columbia. J. Appl. Meteor., 37, 393-404.

_ _ - S. O'Kane, P. Zewar-Reza, and D. Hueff, 1998b: Lower tropospheric ozone measurements by light aircraft equipped with chemiluminescent sonde. J. Atmos. Oceanic Technol., 15, 136-143.

Millan, M. M., E. Mantilla, R. Salvador, A. Carratala, M. J. Sanz, L. Alonso, G. Gangoiti, and M. Navazo, 2000: Ozone cycles in the western Mediterranean basin: Interpretation of monitoring data in complex coastal terrain. J. Appl. Meteor., 39, 487-508.

Mulholland, J. A., A. J. B. Butler, J. G. Wilkinson, A. G. Russell, and P. E. Tolbert, 1998: Temporal and spatial distributions of ozone in Atlanta: Regulatory and epidemiologic implications. J. Air Waste Manage. Assoc., 48, 418-426.

National Research Council, 1991: Rethinking the Ozone Problem in Urban and Regional Air Pollution. National Academy Press, 500 pp.

Peterson, D. L., 2000: Monitoring air quality in mountains: Designing an effective network. Environ. Monit. Assess., 64, 8191.

Pottier, J. L., S. C. Pryor, and R. M. Banta, 1997: Synoptic variability related to boundary layer and surface features observed during Pacific '93. Atmos. Environ., 31, 2163-2173.

Province of British Columbia, cited 2004: Sub-provincial population estimates. [Available online at http://www.bcstats.gov.bc. ca/data/pop/pop/estspop.asp.]

Rosenthal, J. S., R. A. Helvey, T. E. Battalino, C. Fisk, and P. W. Greiman, 2003: Ozone transport by mesoscale and diurnal circulations across southern California. Atmos. Environ., 37 (Suppl. 2), S51-S71.

Schere, K. L., and G. M. Hidy, 2000: Foreword: NARTSO critical reviews. Atmos. Environ., 34, 1853-1860.

Sillman, S., 1993: Tropospheric ozone: The debate over control strategies. Annu. Rev. Energy Environ., 18, 31-56.

Steyn, D. G., and D. A. Faulkner, 1986: The climatology of sea breezes in the Lower Fraser Valley, B.C. Climatol. Bull., 20, 21-39.

_ J. W. Bottehnheim, and R. B. Thomson, 1997: Overview of 
tropospheric ozone in the Lower Fraser Valley, and the Pacific ' 93 field study. Atmos. Environ., 31, 2025-2035.

_ _ K. Ostermann, and P. Bovis, 1999: Meteorology, emissions and ambient air quality during two episodes in the Lower Fraser Valley, B.C. Atmospheric Science Programme, University of British Columbia Internal Rep., $56 \mathrm{pp}$.

— B. B. Ainslie, and I. G. McKendry, 2005: Air pollution in the Lower Fraser Valley, B.C.: Evolution, measurement, modelling and management. Proc. 39th Canadian Meteorological and Oceanographic Society Congress, Richmond, BC, Canada, 127.

Taylor, E., 1992: The relationship between ground-level ozone concentrations, surface pressure gradients, and $850 \mathrm{mb}$ temperatures in the Lower Fraser Valley of British Columbia. Environment Canada Tech. Rep. PAES-92-3, 7 pp.

United Nations Environmental Programme, 1992: Urban Air Pol- lution in Megacities of the World: Earthwatch: Global Environment Monitoring System. Blackwell Reference, 230 pp.

Van Ooy, D. J., and J. J. Carroll, 1995: The spatial variation of ozone climatology on the western slope of the Sierra Nevada. Atmos. Environ., 29, 1319-1330.

Vasanji, Z., and I. S. Gartshore, 1978: An analysis of six simultaneous wind records taken near Vancouver. Atmos.-Ocean, 16, 145-156.

Vingarzan, R., and B. Taylor, 2003: Trend analysis of ground level ozone in the greater Vancouver/Fraser Valley area of British Columbia. Atmos. Environ., 37, 2159-2171.

Weber, R. O., and P. Kaufmann, 1995: Automated classification scheme for wind fields. J. Appl. Meteor., 34, 1133-1141.

_ , and M. Furger, 2001: Climatology of near-surface wind patterns over Switzerland. Int. J. Climatol., 21, 801-827.

Yarnal, B., 1993: Synoptic Climatology in Environmental Analysis. Belhaven Press, 195 pp. 